\title{
Thermal Vacuum Test of Ice as a Phase Change Material Integrated with a Radiator
}

\author{
Steve A. Lee* \\ MEI Technologies, Inc., Houston, TX, 77058 \\ Thomas O. Leimkuehler ${ }^{\dagger}$ \\ Paragon Space Corporation, Houston, TX, 77058 \\ Ryan Stephan ${ }^{\ddagger}$ \\ NASA Johnson Space Center, Houston, TX, 77058 \\ and \\ Hung V. Le $e^{\S}$ \\ Geo Controls, Houston, TX, 77058
}

\begin{abstract}
Water may be used as radiation shielding for Solar Particle Events (SPE) to protect crewmembers in the Lunar Electric Rover (LER). Because the water is already present for radiation protection, it could also provide a mass efficient solution to the vehicle's thermal control system. This water can be frozen by heat rejection from a radiator and used as a Phase Change Material (PCM) for thermal storage. Use of this water as a PCM can eliminate the need for a pumped fluid loop thermal control system as well as reduce the required size of the radiator. This paper describes the testing and analysis performed for the Rover Engineering Development Unit (REDU), a scaled-down version of a water PCM heat sink for the LER. The REDU was tested in a thermal-vacuum chamber at environmental temperatures similar to those of a horizontal radiator panel on the lunar surface. Testing included complete freeze and melt cycles along with scaled transient heat load profiles simulating a 24-hour day for the rover.
\end{abstract}

\section{Nomenclature}

$A_{\text {rad }, L E R}=$ radiator surface area

$A_{\text {rad, }, R E D U}=$ ratio of LER surface area to REDU surface area

$E_{l}=$ combination of latent energy

$E_{s} \quad=$ sensible energy

$E_{t} \quad=$ total energy

$h_{f} \quad=$ heat of fusion for water

$h_{L E R}(t)=$ heat input profile as a function of time for LER

$h_{R E D U}(t)=$ the heat load profile for REDU

$k=$ thermal conductivity of Nomex ${ }^{\circledR}$

$m=$ mass of PCM

$q_{\text {leak }}=$ heat leak

$q_{P C M}=$ heat rate into the PCM

${ }^{*}$ Project Engineer, 2224 Bay Area Boulevard, Mail Code JE-B21N.

† Senior Aerospace Engineer, 1120 NASA Parkway, Suite 505

${ }^{\ddagger}$ Project Manager, Crew and Thermal Systems Division, 2101 NASA Parkway, Mail Code EC2.

$\S$ Project Manager, 2224 Bay Area Boulevard, Mail Code JE-B21N. 


$$
\begin{array}{ll}
q_{\text {rad }} & =\text { heat rate, radiation } \\
t & =\text { time } \\
T_{e n v} & =\text { environment sink temperature (or shroud temperature) } \\
T_{s} & =\text { average radiator surface temperature } \\
T_{\text {side, } 1} & =\text { temperature of the side of REDU (in contact with Nomex }{ }^{\circledR} \text { ) } \\
T_{\text {side, } 2} & =\text { temperature of the side of REDU (exposed) } \\
\Delta t & =\text { time required to melt the PCM } \\
\Delta x & =\text { thickness of the Nomex }{ }^{\circledR}
\end{array}
$$$$
\varepsilon=\text { surface emissivity }
$$$$
\sigma \quad=\text { Stefan-Boltzmann constant }
$$

\section{Introduction}

One concept to expand the range of exploration for return missions to the moon is the Lunar Electric Rover ${ }^{* *}$ (see Fig. 1). To protect crewmembers from radiation due to Solar Particle Events (SPE), the LER is envisioned to have an approximately 4 -inch layer of water in the ceiling, and possibly walls ${ }^{1}$. This water can potentially be frozen by heat rejection from a radiator and used as a phase change material for thermal storage ${ }^{2}$. Use of the PCM can reduce the size requirements of the vehicle's radiator.

There are challenges to using a PCM heat sink in this

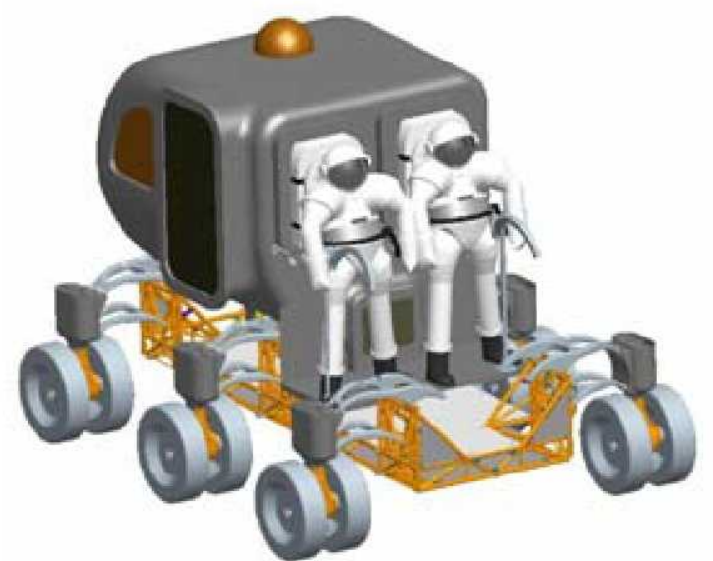

Figure 1. Lunar Electric Rover Concept application. One of the challenges is heat input and removal from opposing sides of the heat sink. Traditionally a PCM heat sink has one interface (e.g., a cold plate) for both input and removal of the thermal energy. Therefore, adequate thermal contact is needed on only one side of the PCM. However, with the water PCM heat sink for the LER, adequate thermal contact is needed on both the fluid side and the radiator side of the PCM. This presents a challenge in increasing the conductance on both sides while ensuring that it is not so high as to provide a "thermal short", bypassing the PCM. The key to this challenge is to ensure that there is sufficient thermal conductance into the phase change material, which will avoid the thermal short by first absorbing the heat before distributing heat to the other side.

Another challenge is preventing the ice from rupturing the container upon freezing. The inclusion of an air gap for volumetric expansion could protect against a rupture; however, transferring heat across that air gap may also present a challenge.

By utilizing a water PCM heat sink on the LER, the following benefits may be realized:

1) Lower the required size of the radiator - By utilizing a phase change material in the design of a thermal control system, the radiator can be sized for the average heat rejection rate, as opposed to the maximum heat rejection rate (see Fig. 2). The phase change material will absorb heat during the high heat loads and be regenerated during periods of low heat load.

2) Remove the need for a pumped fluid loop -

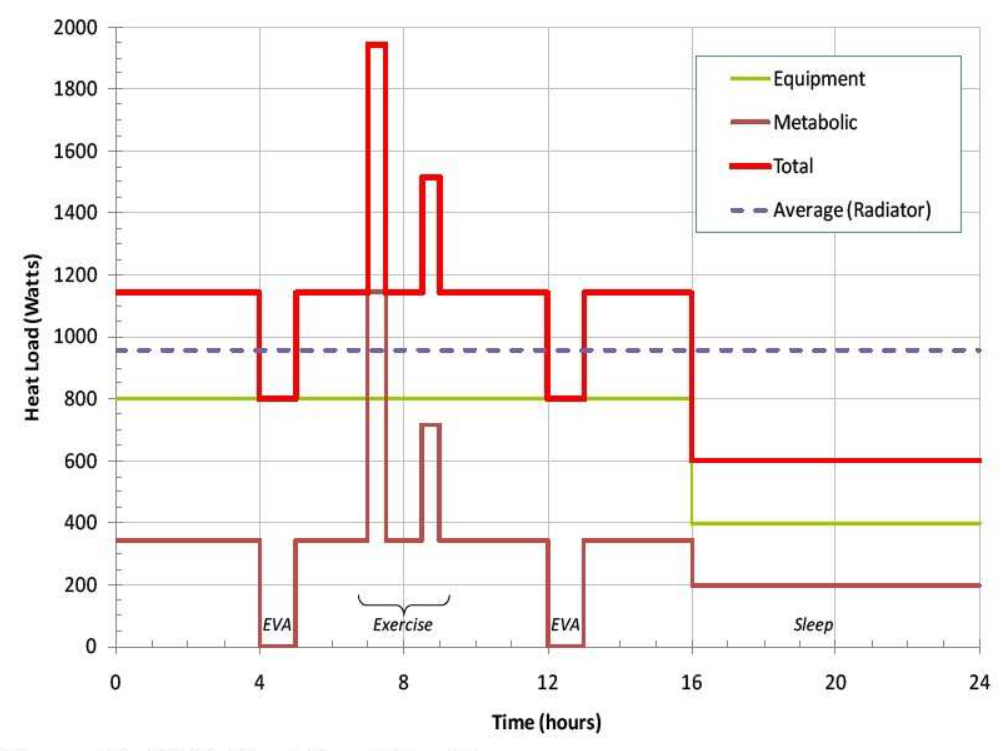
Usually, for high heat load Figure 2. LER Heat Load Profile

${ }^{* *}$ http://www.nasa.gov/exploration/home/LER.html

American Institute of Aeronautics and Astronautics 
systems, especially when using a radiator, a pumped fluid loop is required to transfer heat from equipment to the radiator. However, by coupling the phase change material to the radiator, equipment can be mounted in contact with the phase change material, and the PCM, in turn, transfers heat to the radiator.

3) Simplify the temperature control system - For fluid flow cooled by a radiator, the exit temperature will change with respect to the outside environment, creating a need for a control system to control the radiator exit temperature. However, for a system utilizing PCM, the exit temperature is always controlled to the temperature of the PCM, which should be constant at all times if designed correctly. Therefore, temperature control is much simpler.

\section{Test Setup}

\section{A. Test Article Description}

Testing was performed in a thermal vacuum chamber at Johnson Space Center. Three PCM test articles were evaluated. They were all approximately 12 " long x 12 " wide and differed according to the list that follows:

- REDU-1: Thick fins spaced far apart, 1.5" high (internal dimension)

- REDU-3: Thick honeycomb spaced far apart, 1.5" high (internal dimension)

- REDU-4: Thin honeycomb spaced close together, 1.5 " high (internal dimension)

The general design goal was to test both honeycomb fins and straight fins, both made of aluminum. In addition, the characteristic dimensions of the interstitial materials were chosen to compare thin interstitial walls spaced close together to thicker walls spaced far apart. This design approach would result in two heat sinks with the same effective thermal conductance from top to bottom.

REDU-1 is shown in Fig. 3. Thick fins were machined into a solid piece of 6061 aluminum. All of the test articles, including REDU-1, were partially filled with de-ionized water, leaving a $20 \%$ by volume air space at the top to allow for expansion when freezing. The lids of the test articles, also 6061 aluminum, were screwed on with a gasket to prevent leaks (see Fig. 4). Nomex ${ }^{\circledR}$ insulation covered with aluminized mylar was installed around each of the REDUs to minimize heat leak from the sides and bottom during testing.

REDU-3 and -4 were similar to REDU-1; however, instead of machined fins, REDU-3 and -4 used 5052

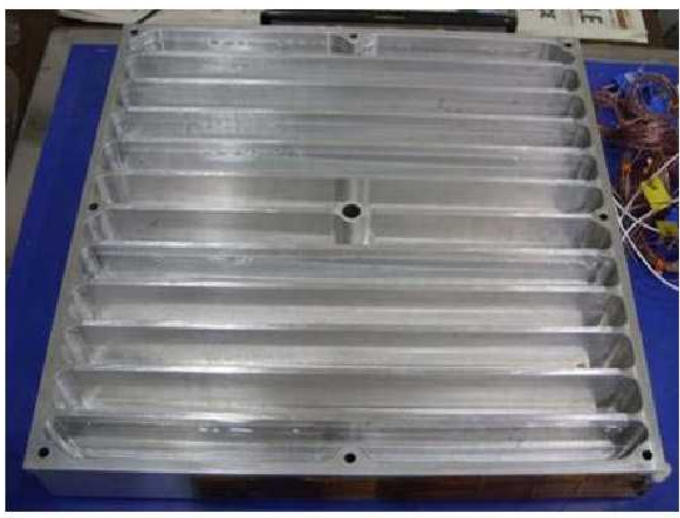

Figure 3. REDU-1 (Thick Fins)

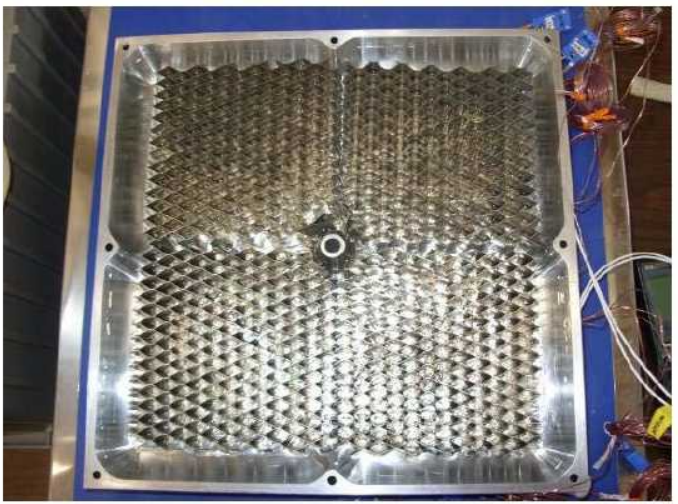

Figure 5. REDU-3 (Thick Honeycomb)

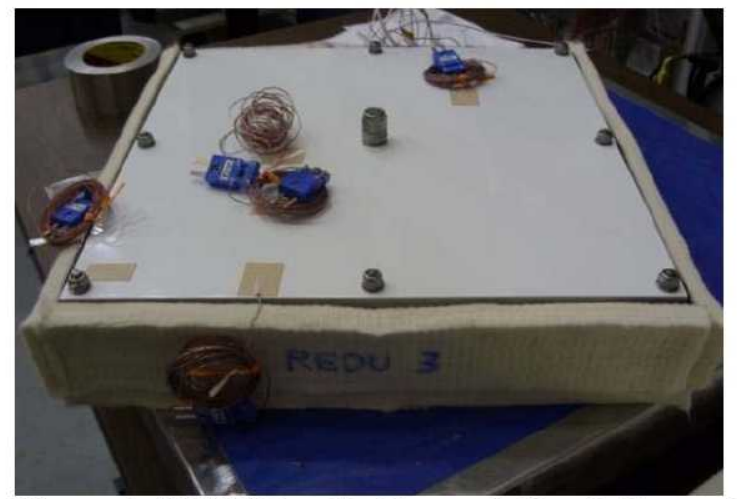

Figure 4. REDU-3 with Nomex® Insulation and Lid

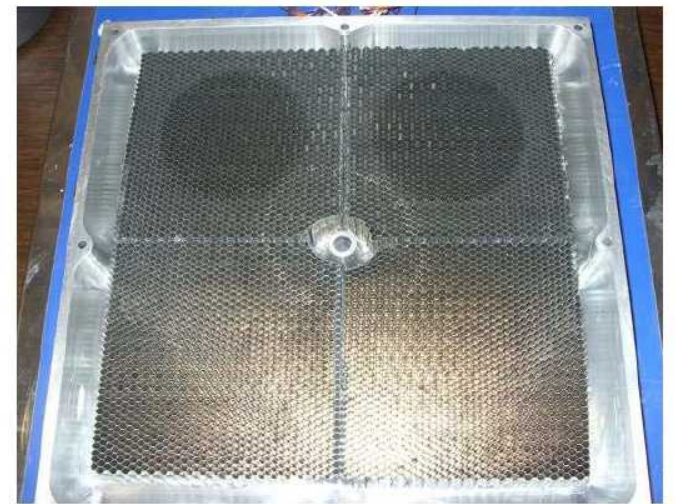

Figure 6. REDU-4 (Thin Honeycomb)

3

American Institute of Aeronautics and Astronautics 
aluminum honeycomb material to conduct heat to the PCM (see Fig. 5 and Fig. 6). To ease manufacturing, the honeycomb was obtained in four pieces per box. Approximately 4 sheets of aluminum foil were installed above and underneath each of the honeycomb layers in order to provide additional height and improve the uniformity of the thermal contact to the lid.

Three heaters were placed underneath each of the test articles to simulate heat load from avionics. Thermocouples were placed on the top, bottom, and sides of each REDU test article, and temperatures were recorded to a data acquisition system during testing.

\section{B. Test Article Assembly in Chamber}

A picture of the test setup is shown in Fig. 7, and a schematic is shown in Fig. 8. The three REDUs were placed on top of Lexan ${ }^{\circledR}$ plates, which were separated from an aluminum base by Teflon ${ }^{\circledR}$ standoffs. Sink temperature coupons were placed in-between each of the test articles and outside of the REDU test articles. The sink temperature coupons were thermally isolated from the test stand using nylon rods. Radiative heat transfer was reduced on the

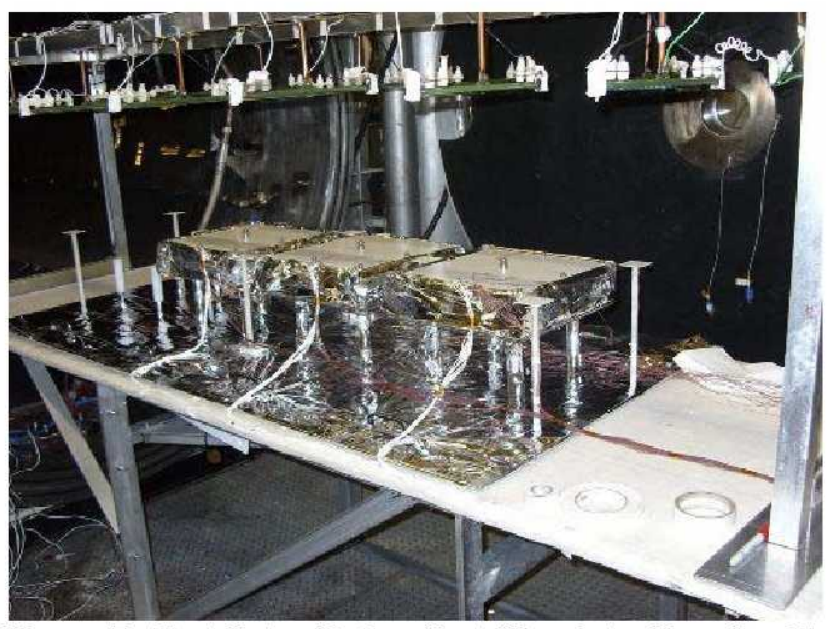

Figure 7. Test Setup Before Installing into Chamber E bottoms and sides of the test articles and coupons by using aluminized Mylar $^{\circledR}$, which has a very low infrared emissivity.

\section{Test Procedure and Anomalies}

A Lunar surface environment temperature at the pole was desired to be simulated for testing. The Polar radiative environmental temperature was calculated to be between $93 \mathrm{~K}$ and $125 \mathrm{~K}\left(-292.3{ }^{\circ} \mathrm{F}\right.$ to $-234.7^{\circ} \mathrm{F}$ ) assuming $\alpha / \varepsilon=0.12$ for the radiator surface. For the purposes of testing, the lowest attainable temperature in the thermal vacuum chamber was achieved to simulate the Polar environment. A pressure of approximately $7 \times 10^{-6}$ Torr was maintained for the duration of testing, unless otherwise noted.

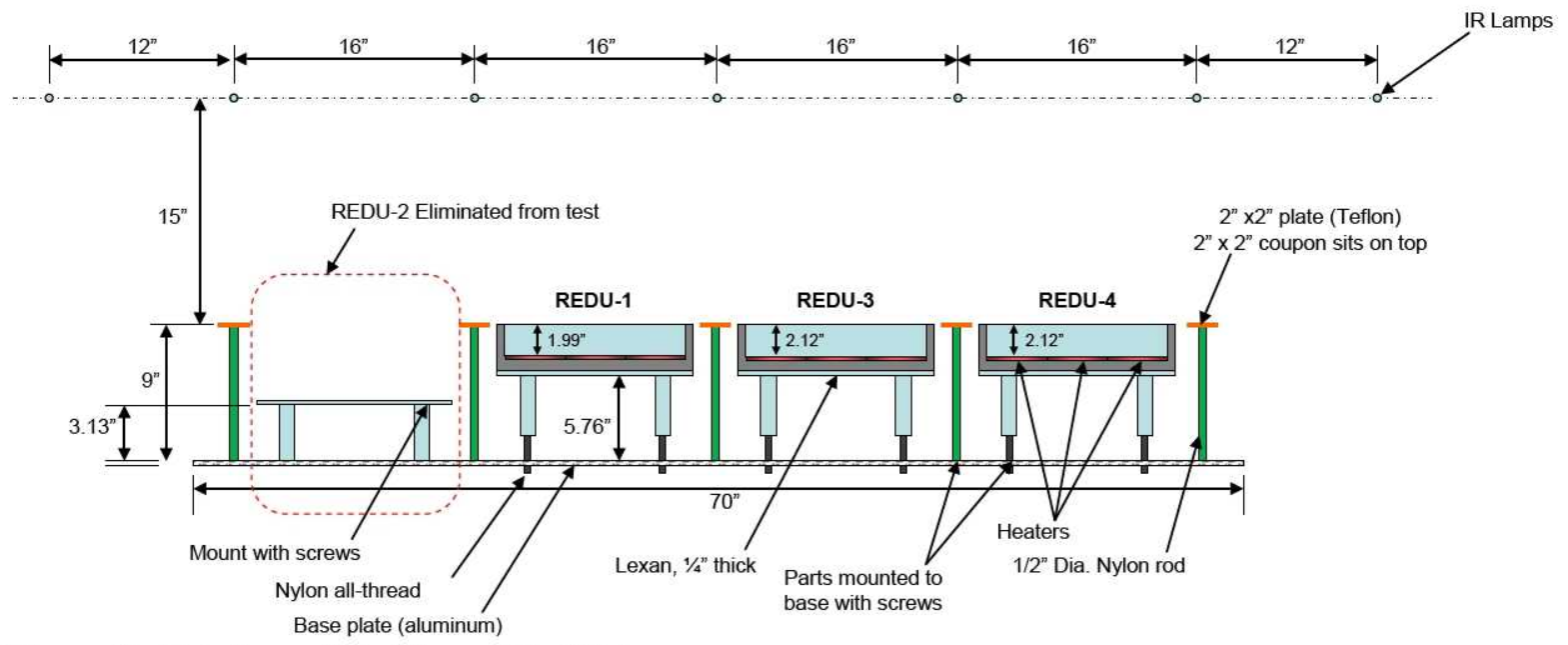

Figure 8. Cut-Away Side View of Test Setup

\section{A. Freeze/Thaw Testing}

The REDUs were to be frozen and then thawed in order to obtain basic performance data. Liquid nitrogen was flowed through a shroud in the vacuum chamber to decrease the environment temperature to approximately $105 \mathrm{~K}$ ($270^{\circ} \mathrm{F}$ ). The REDUs radiated heat to the environment, freezing the PCM. Once the REDUs were completely frozen, the heaters were turned on in order to thaw the PCM. However, a large increase in chamber pressure indicated that at least one of the REDUs was leaking. After some troubleshooting, it was determined that REDU-3 and -4 were likely leaking. Therefore, all subsequent testing continued with only REDU-1. 


\section{B. Steady State Test}

After REDU-1 completed thawing at 70 Watts, the heat load was reduced to approximately 38 Watts in order to maintain a constant radiator surface temperature of approximately $50^{\circ} \mathrm{F}$. The heat loads remained constant for about 4.5 hours in order to ensure that steady state had been achieved.

\section{DITLO (REDU-1)}

A DITLO (a 24-hour "Day In The Life Of" the rover) profile was determined for the LER (see Fig. 2) and was then adapted for use in the REDU test. For the LER, it was assumed that the radiator would be sized to remove the same amount of energy as what was put into the PCM in a 24-hr period. Therefore, the average heat load was used to determine the radiator size, $A$, by solving for $A$ in the equation

$$
q_{\text {rad }}=\frac{\int_{0}^{24 \mathrm{hr}} h_{L E R}(t) d t}{24 \mathrm{hr}}=\varepsilon \sigma A_{r a d, L E R}\left(T_{s}^{4}-T_{e n v}^{4}\right)
$$

where $q_{\mathrm{rad}}$ was rate of heat removed by the radiator,

$h_{L E R}(t)$ was the heat rate input profile as a function of time for LER,

$t$ was time,

$\varepsilon$ was the surface emissivity of the radiator,

$\sigma$ was the Stefan-Boltzmann constant,

$A_{\text {rad,LER }}$ radiator surface area,

$T_{s}$ was the average radiator surface temperature (assumed to equal $0^{\circ} \mathrm{F}$, the phase change temperature), and

$T_{e n v}$ was the environment sink temperature.

It was desired to have the heat flux for REDU be equivalent to the heat flux for LER. Therefore, the heat load profile for REDU, $h_{R E D U}(t)$, was determined by scaling the LER heat load profile using the ratio of LER surface area to REDU surface area, $A_{\text {rad, REDU, }}$ (see Eq. (2)).

$$
\frac{h_{R E D U}(t)}{A_{r a d, R E D U}}=\frac{h_{L E R}(t)}{A_{r a d, L E R}}
$$

Two DITLO test points were conducted. For the first DITLO test point, the PCM never started to melt because the heat input was too low. It was assumed that there was a heat leak not allowing the full heat from the heater to enter the PCM. Therefore, the DITLO power profile was scaled up to compensate for the additional heat leak, estimated to be approximately 6 Watts. This heat leak was determined by performing a simple thermal analysis. The calculated heat leak was verified using empirical data obtained from the test point. After the DITLO power profile was re-scaled, the PCM remained as a two phase mixture for the duration of testing, as was desired.

\section{Analysis and Discussion of Results}

\section{A. Steady State Performance and Heat Leak}

Using the steady state test results of REDU-1, a heat balance of the system was performed. A schematic of the system is shown in Fig. 11. During the steady state test, the heater input power, $q_{h t r}$, remained constant at approximately $38 \mathrm{~W}$. All IR lamps remained off, and the environment sink temperature, $T_{e n v}$, was assumed to be equal to the shroud temperature, $93 \mathrm{~K}$. Heat radiated from the surface of the REDU at an average temperature of $T_{s}=284 \mathrm{~K}\left(52^{\circ} \mathrm{F}\right)$ (determined using the surface thermocouples).

The heat leak, $q_{\text {leak }}$, was determined by solving the heat balance equation

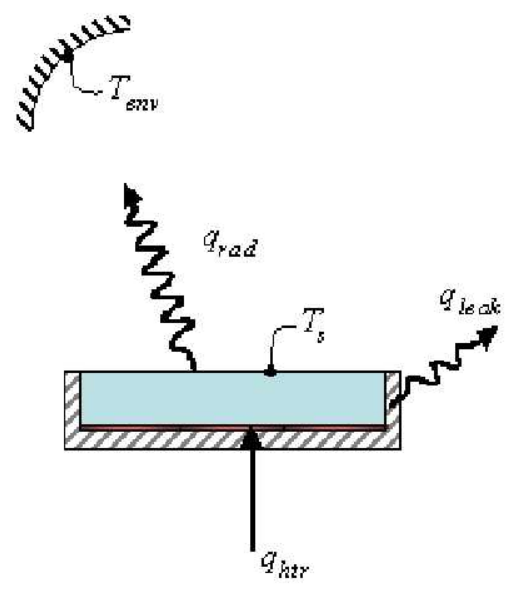

Figure 11. Schematic for Heat Balance 


$$
q_{h t r}-q_{\text {rad }}=q_{\text {leak }}
$$

where $q_{\mathrm{rad}}$ was the rate of heat radiating from the exposed surface of REDU (emissivity assumed to be 0.9 based on manufacturer specifications).

Using Eq. (4), the heat leak from surfaces other than the radiator surface was calculated to be $7.9 \mathrm{~W}$ or $21 \%$ of heat input into the system by the heater. As expected, the calculated conduction heat loss through the Teflon and nylon standoffs was negligible, approximately $0.1 \mathrm{~W}$ for REDU-1. However, heat loss by radiation through the sides and bottom of the REDU was calculated to be approximately $6 \mathrm{~W}$, as described below.

The radiation heat loss was calculated by first utilizing the Fig. 12 to represent the test setup.

Heat loss through the sides of the REDU was calculated by solving the equations

$$
q_{\text {side }}^{\prime \prime}=\varepsilon \sigma\left(T_{\text {side }, 2}^{4}-T_{\text {env }}^{4}\right)
$$

and

$$
q_{\text {side }}^{\prime \prime}=\frac{k}{\Delta x}\left(T_{\text {side }, 1}-T_{\text {side }, 2}\right)
$$

Where $\varepsilon$ was the emissivity of the aluminized mylar (assumed to be 0.08 ),

$\sigma$ was the Stefan-Boltzmann constant,

$k$ was the thermal conductivity of Nomex ${ }^{\circledR}$, $\Delta x$ was the thickness of the Nomex ${ }^{\circledR}$,
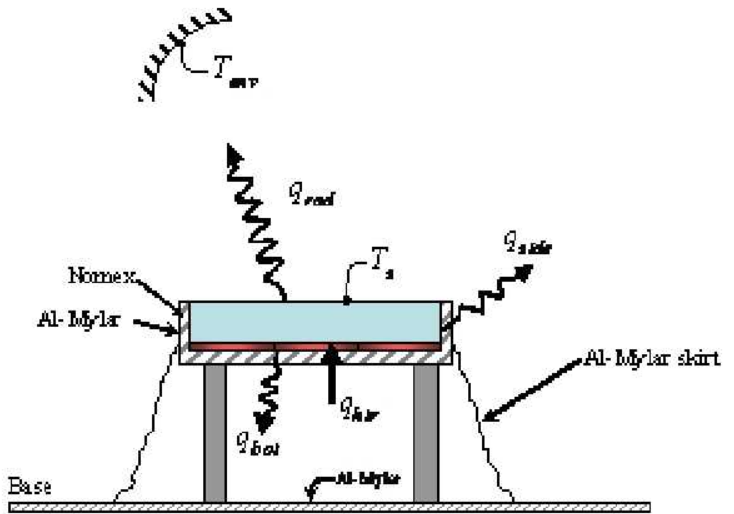

Figure 12. Detailed Schematic for Heat Leak Calculation

$T_{\text {side, } 1}$ was the temperature of the side of the REDU (thermocouple measurement, in contact with Nomex ${ }^{\circledR}$ ),

$T_{s i d e, 2}$ was the temperature of exposed surface on the side of the REDU (calculated), and

$T_{e n v}$ was the environment sink temperature (or shroud temperature).

Heat loss through the base of the REDU was calculated similarly, replacing the base temperature for the environment temperature, since it was assumed that the aluminized mylar skirt was sufficient to block the view of the REDU bottom to the shroud walls.

Since the heat loss from the REDU was significant, it was taken into consideration for all subsequent calculations of thermal performance.

\section{B. Freeze-Thaw Performance}

REDU-1 contained $2.0 \mathrm{~kg}$ of water, which was equivalent to $679 \mathrm{~kJ}$ of thermal storage. Taking heat leak into consideration, the time required to fully melt the PCM was calculated using the equation

$$
q_{P C M}=\frac{m h_{f}}{\Delta t}
$$

Where $m$ was the mass of PCM,

$h_{f}$ was the heat of fusion for water,

$\Delta t$ was the time required to melt the PCM

$q_{P C M}$ was the rate of heat put into the PCM.

The heat rate into the PCM, $q_{P C M}$, was calculated by

$$
q_{P C M}=q_{h t r}-q_{\text {rad }}-q_{\text {leak }}
$$




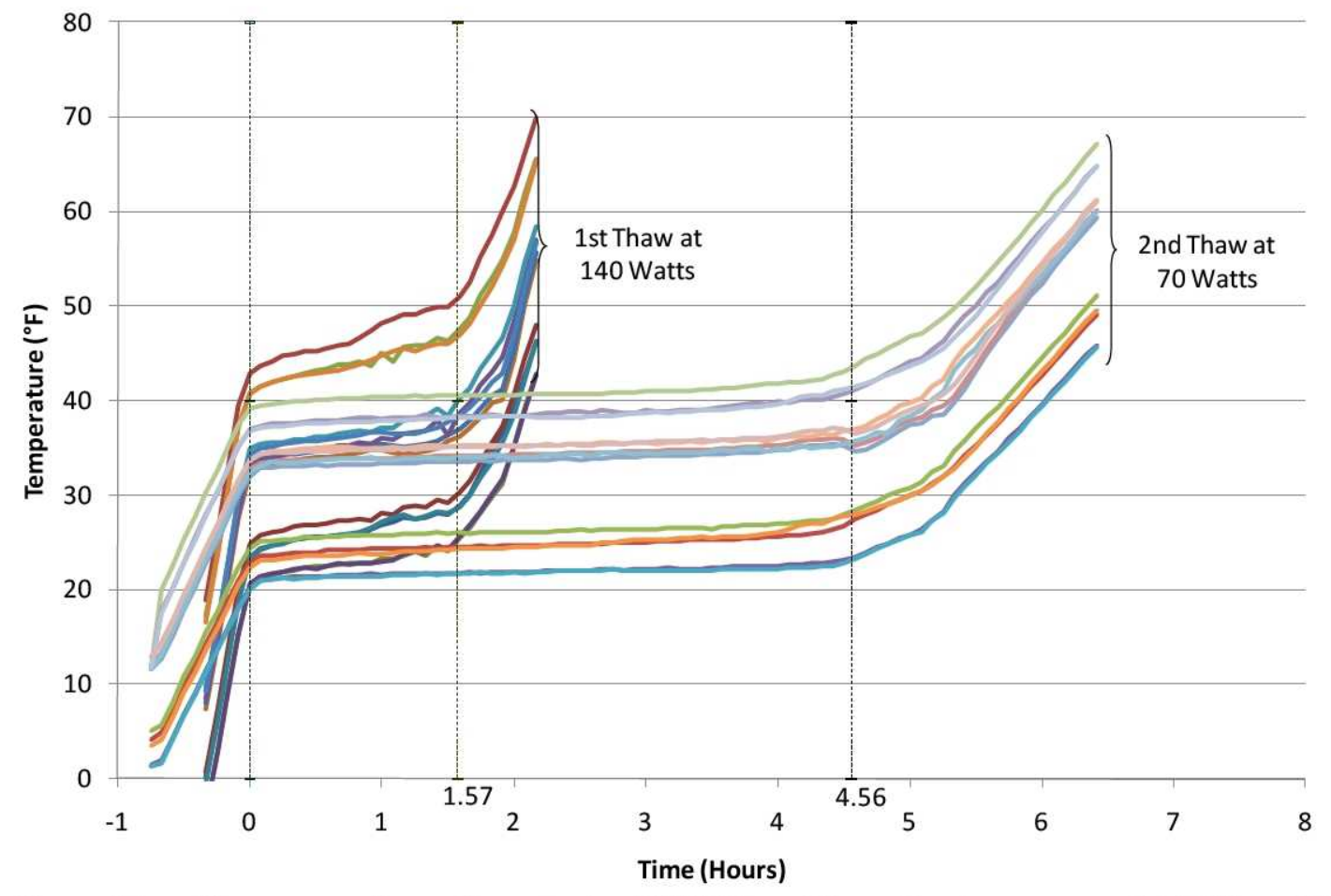

Figure 13. Thermocouple readings during REDU-1 melting at heater powers of $140 \mathrm{~W}$ and $70 \mathrm{~W}$

The calculated time required to melt the PCM at heater inputs of 70 Watts and 140 Watts were $4.7 \mathrm{hrs}$ and 1.7 hrs, respectively. By using the plotted temperature results, shown in Fig. 13, the start and end times for thawing of the PCM were estimated by identifying the times at which the slope changed from nearly horizontal (during phase change). The first thaw (at 140 Watts) completed in approximately $1.6 \mathrm{hrs}$. The second thaw (at 70 Watts) completed in approximately $4.6 \mathrm{hrs}$. Both thaw time results compared well with calculated values, especially when considering that the numerical results were based on estimates from graphical data.

A more detailed analysis can also be performed to determine the latent heat storage from the test data. To begin with, consider that the total energy, $E_{t}$, stored in a PCM is a combination of latent energy, $E_{l}$, and sensible energy, $E_{s}:$

$$
E_{t}=E_{l}+E_{s}
$$

By integrating Eq. (8) over time, we get the total energy storage:

$$
E_{t}=\int_{t} q_{P C M} d t=\int_{t}\left(q_{h t r}-q_{\text {rad }}-q_{\text {leak }}\right) d t
$$

From the data, $q_{h t r}, q_{r a d}$, and $q_{\text {leak }}$ appeared to be fairly constant during a melt cycle. With this assumption, then

$$
E_{t}=\left(q_{h t r}-q_{\text {rad }}-q_{\text {leak }}\right) \Delta t
$$

Now consider two different melt cycles with two different heater powers, $q_{1}$ and $q_{2}$

$$
E_{1}=\left(q_{1}-q_{\text {rad }}-q_{\text {leak }}\right) \Delta t_{1}
$$




$$
E_{2}=\left(q_{2}-q_{\text {rad }}-q_{\text {leak }}\right) \Delta t_{2}
$$

If the beginning and end of the melt cycle durations correspond to the same thermal condition for both cycles, then the total energy is the same. Setting Eqs. (12) and (13) equal to each other, the sum of the radiator heat rejection and the corresponding heat leak can be solved:

$$
q_{\text {rad }}+q_{\text {leak }}=\frac{q_{2} \Delta t_{2}-q_{1} \Delta t_{1}}{\Delta t_{2}-\Delta t_{1}}
$$

This value can then be used with Eqs. (12) or (13) to determine the total energy input to the PCM during the melt cycle.

Once the total energy is determined, then the sensible energy can be subtracted to arrive at the latent energy. The sensible energy can be calculated from the masses, specific heats, and temperature change of the various components of the REDU box. Even though the starting and ending conditions of the melt cycle may not be isothermal, as long as each component undergoes the same change in temperature during the melt cycle, this approach may be used. The assumption of the same change in temperature is backed up by the lines of temperature vs. time being parallel to each other before and after the phase change portion as observed above in Fig. 13.

Using this method the specific latent heat of the PCM (water) was calculated to be $295 \mathrm{~kJ} / \mathrm{kg}$, which was within approximately $11 \%$ of the accepted value of $333 \mathrm{~kJ} / \mathrm{kg}$.

\section{Conductance}

The conductance across the unit is an important parameter in the design of a PCM. Interstitial material is typically inserted into a PCM to improve its effective thermal conductivity and minimize the difference between the heat input temperature and the temperature of the PCM. A plot of this temperature difference is shown in Fig. 14, where the temperature difference is between the heater surface temperature and the radiator surface temperature. It should be noted that due to the heat leak, not all of the heater power was being transferred across the unit.

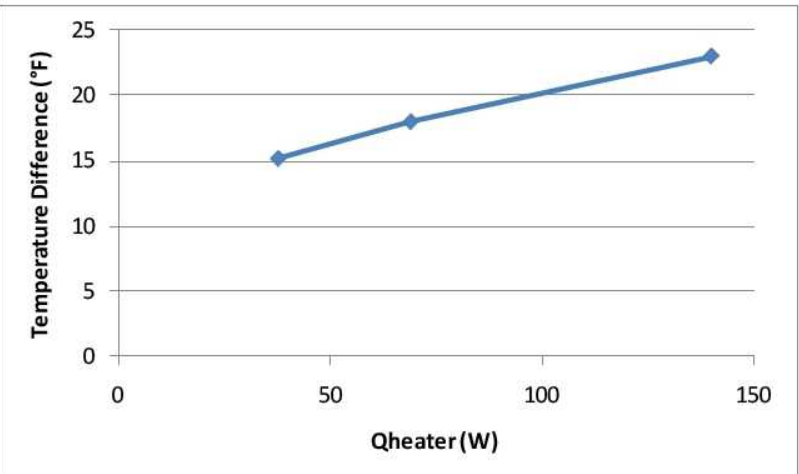

Figure 14. Temperature difference across REDU-1 vs. heater power

\section{DITLO 2 (Rescaled)}

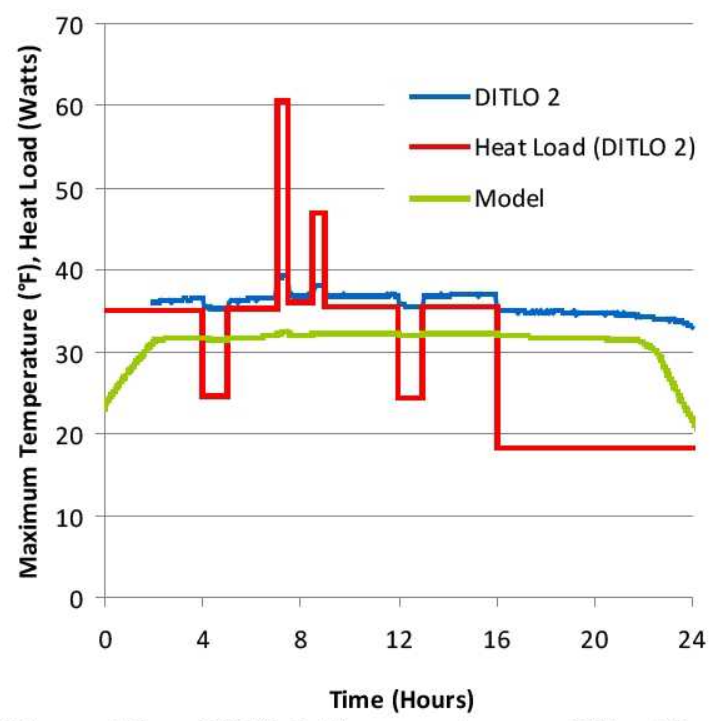

\section{DITLO Performance}

A thermal model, created and run before testing,

\section{Figure 15. DITLO Temperature and Heat Loads}

simulated DITLO and was compared to the test results (see Fig. 15). "DITLO 1" never started to melt ice, as was intended, and was therefore not analyzed. "DITLO 2 (Rescaled)" did maintain a two-phase mixture during the majority of the test point, as intended. However, during the test, the PCM did not completely refreeze by the end of the $24 \mathrm{hr}$ DITLO period.

The fraction of PCM used in DITLO 2 was calculated from the formula below and plotted in Fig. 16. 


$$
\text { Fraction PCM Used }=\frac{\int_{0}^{t} q_{P C M} d t}{m h_{f}}=\frac{\int_{0}^{t}\left(q_{h t r}-q_{\text {rad }}-q_{\text {leak }}\right) d t}{m h_{f}}
$$

where $m$ was the mass of PCM,

$h_{f}$ was the heat of fusion for water,

$q_{P C M}$ was the rate of heat put into the PCM (calculated from Eq. (8), and

$t$ was time.

From the data in Fig. 16, $43 \%$ of the PCM remained melted at the end of DITLO 2. However, the test had been designed to completely freeze the PCM by 24 hours. In other words, the PCM used was expected to equal $0 \%$ at 24 hours into DITLO 2. When comparing the differences between the predicted performance and actual performance for DITLO 2 (see Table 2), it was shown that the actual heat removed from the system was $3.8 \mathrm{~W}$ less than shown in the pretest analytical predictions. (The actual heat load profile, or heater power, was the same as the predicted heat load, since that was a test input.) In other words, approximately $3.8 \mathrm{~W}$ of additional

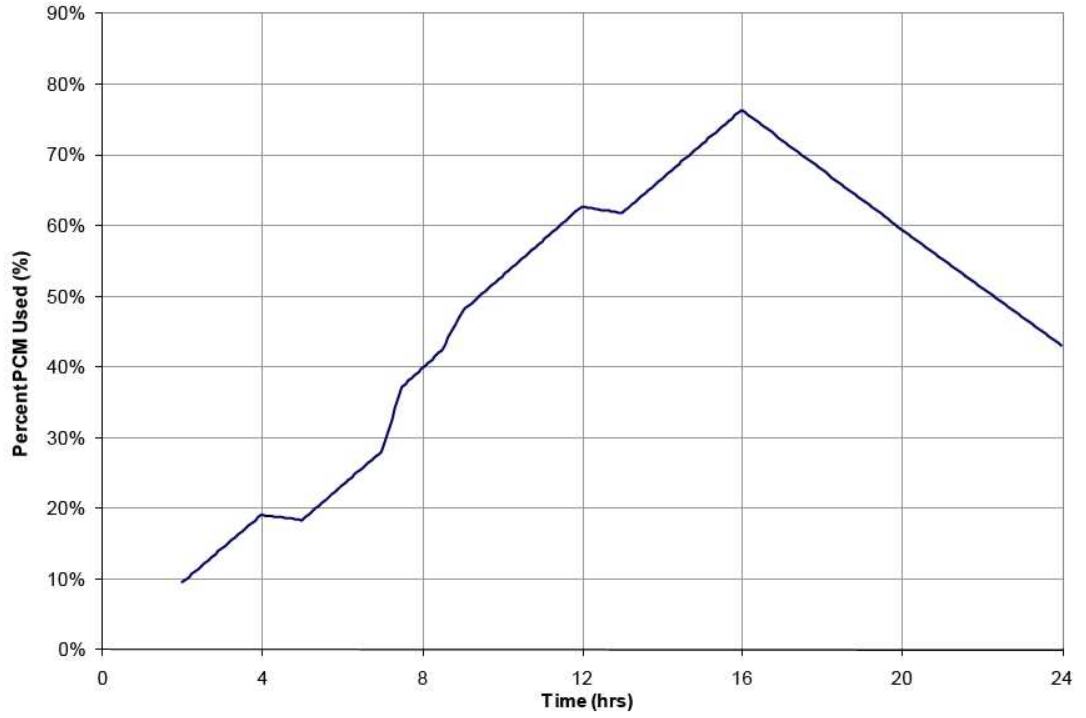

Figure 16. Percentage of PCM Used in DITLO 2 heat was input in the PCM during the test, which accounted for an additional $328 \mathrm{~kJ}$, or $48 \%$ of Table 2. Comparison of Predicted and Actual melted PCM, which is close to the $43 \%$ remaining melted Heat Loads for DITLO 2 PCM observed in the test.

The model seemed to correlate to the test well, taking into account the differences in heat leak and radiation values. This also means that the radiator temperature cannot be assumed to be $273 \mathrm{~K}\left(32^{\circ} \mathrm{F}\right)$ for purposes of sizing. The actual surface temperature during testing was $268 \mathrm{~K}\left(23^{\circ} \mathrm{F}\right)$. A wellcorrelated model should be used to predict the radiator

\begin{tabular}{|l|l|l|}
\hline & Actual & Predicted \\
\hline Heater Power (W) & (same) & $($ same $)$ \\
\hline Heat Leak (W) & 4.65 & 6.0 \\
\hline Radiator (W) & 21.5 & 24.0 \\
\hline Heat Leak + Rad (W) & 26.2 & 30.0 \\
\hline
\end{tabular}
temperature before sizing the radiator.

\section{Conclusion}

Three REDU test articles were tested in a thermal-vacuum chamber under simulated Polar lunar surface conditions. Two of the test articles had problems with leaks, possibly due to corrosion and subsequent generation of gas. Since the LER design will likely require the use of aluminum materials, corrosion protection will need to be considered for future LER PCM concepts.

The REDU test article with thick fins, REDU-1, did not show signs of leaking during the test and was able to continue testing. While heat leak was determined to be significant, it was accounted for in the post test data reduction and analysis. The time required to thaw the PCM was as expected, verifying the assumed heat capacity. The actual phase change temperature of the PCM was unverified since there were no internal thermocouples. The radiator surface temperature of REDU ranged between $23^{\circ} \mathrm{F}$ and $25^{\circ} \mathrm{F}$ during periods of phase change during all test points, which was lower than expected. It was undetermined if the phase change temperature was depressed due to the corrosion occurring inside the enclosure. The low surface temperature may have also been caused by insufficient contact to the interstitial material. The transient thermal model of REDU for the DITLO test point was similar to the 
test results; however, the model will need to be adjusted to match the heat leak and surface temperatures observed in the test.

This testing has demonstrated proof-of-concept that the REDU design can work as a thermal heat sink and radiator. When designed properly (taking into account correct surface temperature and heat leak), the REDU will operate for an indefinite number of cycles without exhausting the phase change material, which will be regenerated at the end of each day.

\section{Acknowledgments}

The authors thank Kevin Ehlinger for helping to make the testing of the REDU a success.

\section{References}

${ }^{1}$ Gernhardt, M., Extravehicular Activities (EVA) and Pressurized Rovers, AIAA Space 2007 Conference and Exposition.

${ }^{2}$ Stephan, R. A., Overview of NASA's Thermal Control System Development for Exploration Project, SAE Paper 2009-012436, 39th International Conference on Environmental Systems (ICES), Savannah, Georgia, July 2009 